\title{
Attractiveness of Black Shannon Trap for Phlebotomines
}

\author{
EAB Galati/ ${ }^{+}$, VLB Nunes*, MEC Dorval**, G Cristaldo**, HC Rocha**, \\ RM Gonçalves-Andrade***, G Naufel
}

\begin{abstract}
Departamento de Epidemiologia, Faculdade de Saúde Pública, USP, Av. Dr. Arnaldo 715, 01246-904 São Paulo, SP, Brasil *Centro de Ciências Biológicas, Agrárias e da Saúde, Uniderp, Campo Grande, MS, Brasil **Departamento de Patologia, Centro de Ciências Biológicas e da Saúde, UFMS, Campo Grande, MS, Brasil ***Laboratório de Imunoquímica, Instituto Butantan, São Paulo, SP, Brasil
\end{abstract}

A white Shannon-type trap was used for captures of female sand flies in the search for natural infection with flagellates, however, due to its low productivity and as a large number of phlebotomines settled on the researchers' black clothes, we decided to compare the relative attractiveness of black and white Shannon-type traps for sand flies. Several pairs of black and white traps were placed side by side in front of caves in four areas in the Serra da Bodoquena, Bonito county, State of Mato Grosso do Sul, Brazil, for a total of 12 observations and 44 h of capture. The experiment resulted in 889 phlebotomines captured, 801 on the black and 88 on the white trap, representing 13 species. The hourly Williams' means were 8.67 and 1.24, respectively, and the black/white ratio was 7.0:1.0. Lutzomyia almerioi, an anthropophilic species closely associated with caves, was predominant (89\%). Only two other species, Nyssomyia whitmani and Psathyromyia punctigeniculata, also anthropophilic, were significantly attracted to the black rather than to the white trap $\left(\chi^{2}\right.$ test; $\left.p \leq 0.01\right)$. The difference between the diversity index of the two traps was not significant at level 0.05. The black trap in these circumstances was much more productive than the white, especially for anthropophilic species.

Key words: attractiveness - caves - Diptera - Phlebotominae - traps

Shannon (1939) described a trap, made of white cloth and mosquito netting, to attract and capture mosquitoes, using animal or light baits. It consisted of a large central compartment and two smaller lateral ones. The measurements, in metres (width, length and height), of the central and the lateral compartments were, respectively: $1.3 \times 3 \times 2$ and $0.6 \times 3 \times 1.3$. This trap is suspended by cords from trees or other supports. Similar traps entirely made of cotton cloth and with smaller dimensions are frequently used in studies of Culicidae (Service 1993) and Phlebotominae (Maroli et al. 1997).

Another version of the Shannon trap, which consists of the central part only, with its top of cloth and sides of mosquito netting was also proposed

This work was supported by Fapesp, process no. 97/ 06438-3.

Licences for research in the caves quoted: IPHAN/ $14^{\mathrm{a}} \mathrm{CR} / 11$ no. 025/98 (Lago Azul Cave); IBAMA/ DIREC/CECAV - no. 008/98 (Pitangueiras, São Miguel and Lago Azul caves); no.010/98 (Guaicurus Settlement) ${ }^{+}$Corresponding author. Fax: +55-11-3081.2108. E-mail: egalati@usp.br

Received 31 August 2000

Accepted 8 March 2001 by Shannon (1939), and the capture of the insects is made both inside and outside this single compartment. In studies of phlebotomines, Maroli et al. (1997) used a trap with a single compartment and Perez et al. (1988) used this model with measurements of $1.6 \times 2.5 \times 1.6 \mathrm{~m}$. Vexanet et al. (1986) showed another modification of the Shannon trap, in which the central compartment was replaced by a cloth hanging vertically from the top, and the lateral compartments, although shallower, were maintained.

Independently of the modifications the Shannon trap has undergone, the presence of man during the captures means that he also plays the role of bait, as well as the light of the lantern or any other source. The importance of the anthropophily of the species in relation to the efficiency of the trap was demonstrated by Perez et al. (1988) in a comparative study of human baited and non-baited traps, when it was observed that the presence of phlebotomines in the latter seemed to occur merely by chance.

According to Browne and Bennett (1981), observations on the greater attractiveness of dark rather than light colours for mosquitoes are not new and this behaviour may be a response to surfaces with lower reflective capacity (Brett 1938). It is the spectral reflectance of the colours which influences their choice by mosquitoes (Gjullin 1947). 
For some females of Aedes, the attraction exercised by coloured cloths as landing surfaces varies inversely with their brightness, as measured by the reflectivity for light, with wavelengths between 475 and $625 \mathrm{~nm}$ (Brown 1954). Different species of the same genus respond differently to the same visual stimuli (Gilbert \& Gouck 1957) but, on the other hand, a particular behavioural response is common to different species (Sippel \& Brown 1953).

On the basis of a previous successful capture of females, to search for natural infection with flagellates, in an area covered by "cerradão", a type of savanna vegetation (Galati et al. 1996), using a white modified Shannon trap, like that employed by Vexanet et al. (1986), we decided to use the same model in a project to study the bio-ecology of phlebotomines in the Speleological Province of the Serra da Bodoquena, also an area of "cerradão". However, the number of phlebotomines settling on the walls of the trap was very small or non-existent; on the other hand, there was a large number of them on the researchers' clothes, especially when these were black.

Due to the fact that for some species of insects dark colours are more attractive and also due to the need to increase the number of females captured, we decided to compare black and white modified Shannon traps and the results of this experiment are presented here.

\section{MATERIALS AND METHODS}

The study was undertaken in the Serra da Bodoquena $\left(19^{\circ} 48^{\prime}-22^{\circ} 16^{\prime} \mathrm{SL}\right.$ and $56^{\circ} 32^{\prime}-57^{\circ} 24^{\prime}$ WL; 400-650 m.a.s.1.), State of Mato Grosso do Sul, Brazil, in four areas of Bonito county, from June 1998 to March 1999.

The ground where the traps were installed was calcareous with occasional exposed rocks and loose stones, covered with "cerradão" vegetation. The observations were made in the following four environments: (i) Guaicurus Settlement, in a homefarm belonging to Mr José Barbosa, in the peridomicile, about $10 \mathrm{~m}$ from the domicile, $5 \mathrm{~m}$ from a small vertical rocky cave and $6 \mathrm{~m}$ from a hill covered with residual native vegetation; (ii) São Miguel Farm, in front of the cave of the same name (MS-09), $6 \mathrm{~m}$ from its mouth; (iii) Gruta do Lago Azul (MS-02), close to the steps that lead down to the lake at the bottom of the cave; and (iv) Pitangueiras Farm, in front of the cave of the same name (MS-38), $3 \mathrm{~m}$ from its mouth.

The measurements of the traps were, in metres (width, length and height, respectively), 1.4 x 1.6 $\mathrm{x} 1.5$ and the height of the sides $0.4 \mathrm{~m}$ (Figure).The two traps, the black and the white, at each locality, having their relative position alternated for each successive capture, were set side by side, between $5 \mathrm{pm}$ and $10 \mathrm{pm}$, for a total of 12 observations and $44 \mathrm{~h}$ of capture. A fluorescent lamp (15 W, $12 \mathrm{~V})$, hanging between the two traps, and a manual lantern $(0.15 \mathrm{~A}, 6 \mathrm{~V})$ were used as light source. In each trap the captures were made by one researcher only, but no necessary the same person. When few insects settled on a trap they were captured with a collecting tube, but when there were too many, we used an aspirator (Natal \& Marucci 1984).

Statistical analysis - The estimates of diversity between the traps were obtained using the Indices of Fisher et al. and Margalef (Service 1993, Hayek \& Buzas 1997) and for the similarity between them, Sorensen's quotient (Service 1993) was employed. The relative attractiveness between black and white modified Shannon traps for the total of the localities above mentioned was assessed by the $\chi^{2}$ test, for $\mathrm{N} \geq 10$, and by the binomial test, when $5 \leq \mathrm{N} \leq$ 9 (Siegel 1975). The hourly frequency was obtained by the Williams' mean (Haddow 1960).

The species nomenclature used is that of Galati (1995).

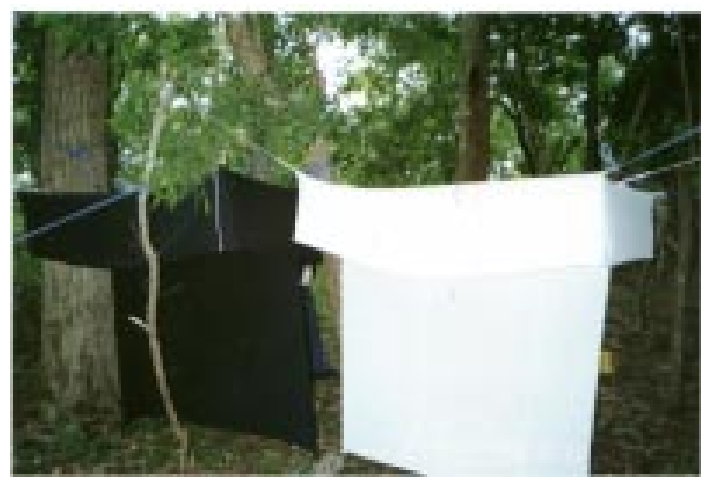

The pair of modified Shannon traps in black and white situated in front of the São Miguel mouth cave.

\section{RESULTS}

The captures resulted in 889 sand flies, 801 on the black and 88 on the white traps, representing 13 species. In the total capture, a new species, Lutzomyia almerioi, described by Galati and Nunes (1999) exercised an absolute predominance at all sites, both on the black and the white traps. The second most frequent species was Nyssomyia whitmani (Table I). Among the species with total frequency $(\mathrm{N})$ equal to or greater than 10 , on the two traps, L. almerioi, N. whitmani, Psathyromyia punctigenicula and $P$. shannoni were more frequently captured on the black trap, but, only for the first three species, was the difference statistically significant at a level of $p \leq 0.01$. Of the spe- 


\section{TABLE I}

Number and percentage of phlebotomines of both sexes captured with modified black (B) and white (W) Shannon traps near cave mouths, in four localities in Bonito county, State of Mato Grosso do Sul, Brazil, between June 1998 and March 1999

\begin{tabular}{|c|c|c|c|c|c|c|c|c|c|c|c|c|c|c|c|c|c|c|c|c|}
\hline Localities & \multicolumn{4}{|c|}{ Guaicurus } & \multicolumn{4}{|c|}{ São Miguel } & \multicolumn{4}{|c|}{ Lago Azul } & \multicolumn{4}{|c|}{ Pitangueiras } & \multicolumn{4}{|c|}{ Overall $^{a}$} \\
\hline Hours of capture & \multicolumn{4}{|c|}{7} & \multicolumn{4}{|c|}{9} & \multicolumn{4}{|c|}{11} & \multicolumn{4}{|c|}{17} & \multicolumn{4}{|c|}{44} \\
\hline \multirow[t]{2}{*}{ Species } & \multicolumn{2}{|c|}{ B } & \multicolumn{2}{|c|}{ W } & \multicolumn{2}{|c|}{$\mathrm{B}$} & \multicolumn{2}{|c|}{ W } & \multicolumn{2}{|c|}{$\mathrm{B}$} & \multicolumn{2}{|c|}{ W } & \multicolumn{2}{|c|}{ B } & \multicolumn{2}{|c|}{ W } & \multicolumn{2}{|c|}{ B } & \multicolumn{2}{|c|}{ W } \\
\hline & $\mathrm{N}$ & $\%$ & $\mathrm{~N}$ & $\%$ & $\mathrm{~N}$ & $\%$ & $\mathrm{~N}$ & $\%$ & $\mathrm{~N}$ & $\%$ & $\mathrm{~N}$ & $\%$ & $\mathrm{~N}$ & $\%$ & $\mathrm{~N}$ & $\%$ & $\mathrm{~N}$ & $\%$ & $\mathrm{~N}$ & $\%$ \\
\hline Brumptomyia sp. & - & - & - & - & - & - & - & - & 1 & 1 & 1 & 4.5 & - & - & 1 & 1.8 & 1 & 0.1 & 2 & 2.3 \\
\hline Evandromyia corumbaensis & - & - & 1 & 25 & - & - & 1 & 16.7 & - & - & - & - & 1 & 0.2 & - & - & 1 & 0.1 & 2 & 2.3 \\
\hline Evandromyia teratodes & - & - & - & - & - & - & - & - & 1 & 1 & 1 & 4.5 & - & - & - & - & 1 & 0.1 & 1 & 1.1 \\
\hline Lutzomyia almerioi & 22 & 53.7 & 1 & 25 & 47 & 69.1 & 2 & 33.2 & 88 & 84.5 & 13 & 59.1 & 579 & 98.4 & 42 & 75 & 736 & 92 & 58 & 66 \\
\hline Lutzomyia longipalpis & 2 & 4.9 & - & - & - & - & 1 & 16.7 & - & - & - & - & - & - & - & - & 2 & 0.2 & 1 & 1.1 \\
\hline Martinsmyia oliveirai & - & - & - & - & - & - & - & - & - & - & - & - & 1 & 0.2 & - & - & 1 & 0.1 & - & - \\
\hline Micropygomyia peresi & - & - & & - & 1 & 1.5 & - & - & - & - & - & - & 1 & 0.2 & 3 & 5.4 & 2 & 0.2 & 3 & 3.4 \\
\hline Micropygomyia quinquefer & - & - & - & - & - & - & - & - & - & - & - & - & 2 & 0.3 & 6 & 10.7 & 2 & 0.2 & 6 & 6.8 \\
\hline Nyssomyia whitmani & 13 & 31.7 & 1 & 25 & 5 & 7.4 & - & - & 2 & 1.9 & 1 & 4.5 & 4 & 0.7 & 4 & 7.1 & 24 & 3 & 6 & 6.8 \\
\hline Pintomyia sp. & 3 & 7.3 & - & - & 2 & 2.9 & - & - & 1 & 1 & 1 & 4.5 & - & - & - & - & 6 & 0.8 & 1 & 1.1 \\
\hline Psathyromyia punctigeniculata & - & - & - & - & 8 & 11.8 & 1 & 16.7 & 1 & 1 & 1 & 4.5 & - & - & - & - & 9 & 1.1 & 2 & 2.3 \\
\hline Psathyromyia shannoni & 1 & 2.4 & 1 & 25 & 3 & 4.4 & 1 & 16.7 & 5 & 4.8 & 2 & 9.2 & - & - & - & - & 9 & 1.1 & 4 & 4.5 \\
\hline Sciopemyia sordellii & - & - & - & - & 2 & 2.9 & - & - & 5 & 4.8 & 2 & 9.2 & - & - & - & - & 7 & 1 & 2 & 2.3 \\
\hline Total & 41 & 100 & 4 & 100 & 68 & 100 & 6 & 100 & 104 & 100 & 22 & 100 & 588 & 100 & 56 & 100 & 801 & 100 & 88 & 100 \\
\hline
\end{tabular}

a: $\chi^{2} 1 \mathrm{fd}:$ L. almerioi $=2137.5 \mathrm{p}<0.0001 ; N$. whitmani $=16.9 \mathrm{p}<0.001 ;$ P. punctigeniculata $=7.5 \mathrm{p}<0.01 ;$. shannoni $=2.3$ (NS at 0.05 level)

Binomial test: $M$. peresi $\mathrm{p}=0.5 ; P$. quinquefer $\mathrm{p}=0.15 ;$ Pintomyia $\mathrm{sp} . \mathrm{p}=0.06 ;$ S. sordellii $\mathrm{p}=0.09$ 
TABLE II

Hourly Williams' mean for both sexes by species of phlebotomines captured with black and white traps, at the four localities between June 1998 and March 1999 and the black/white ratio of this mean

\begin{tabular}{|c|c|c|c|}
\hline Species & Black & White & $\begin{array}{c}\text { Black/White } \\
\text { Ratio }\end{array}$ \\
\hline Brumptomyia sp. & 0.016 & 0.032 & $0.5: 1.0$ \\
\hline Evandromyia corumbaensis & 0.016 & 0.032 & $0.5: 1.0$ \\
\hline Evandromyia teratodes & 0.016 & 0.016 & 1.0:1.0 \\
\hline Lutzomyia almerioi & 7.739 & 0.699 & $11.1: 1.0$ \\
\hline Lutzomyia longipalpis & 0.025 & 0.016 & 1.6:1.0 \\
\hline Martinsmyia oliveirai & 0.016 & - & - \\
\hline Micropygomyia peresi & 0.032 & 0.048 & $0.7: 1.0$ \\
\hline Micropygomyia quinquefer & 0.032 & 0.099 & $0.3: 1.0$ \\
\hline Nyssomyia whitmani & 0.284 & 0.085 & $3.3: 1.0$ \\
\hline Pintomyia sp. & 0.092 & 0.016 & $5.7: 1.0$ \\
\hline Psathyromyia punctigeniculata & 0.127 & 0.032 & 4.0:1.0 \\
\hline Psathyromyia shannoni & 0.145 & 0.065 & $2.2: 1.0$ \\
\hline Sciopemyia sordellii & 0.484 & 0.032 & $1.5: 1.0$ \\
\hline Total & 8.667 & 1.243 & 7.0:1.0 \\
\hline
\end{tabular}

cies for which $5 \leq \mathrm{N} \leq 9$, Micropygomyia peresi and $M$. quinquefer were more attracted to the white and Pintomyia sp. and Sciopemyia sordellii to the black, but the difference was not statistically significant at the 0.05 level for any of them. Except for a single Martinsmyia oliveirai, captured on a black trap, the species were all represented in the captures on both traps (Table I).

The hourly Williams' means for species captured with black and white traps respectively, and the black/white ratio at the four localities are presented in Table II. The hourly Williams' means and the black and white ratio for all the species according to their localities are shown in Table III.

A comparison between Williams' means of females and males of L. almerioi according to their localities on the black and white traps, respectively, is presented in Table IV.

\section{TABLE III}

Hourly Williams' mean for both sexes and all species captured with black and white modified Shannon traps, in the four localities, between June 1998 and March 1999

\begin{tabular}{lccr}
\hline $\begin{array}{l}\text { Localities } \\
\text { Traps }\end{array}$ & Black & White & $\begin{array}{r}\text { Black/White } \\
\text { Ratio }\end{array}$ \\
Guaicurus & 3.43 & 0.35 & $9.8: 1.0$ \\
São Miguel & 6.14 & 0.56 & $11.0: 1.0$ \\
Lago Azul & 6.48 & 1.08 & $6.0: 1.0$ \\
Pitangueiras & 16.32 & 2.31 & $7.1: 1.0$ \\
\hline Overall & 8.67 & 1.24 & $7.0: 1.0$ \\
\hline
\end{tabular}

The measurements of similarity and diversity for the black and the white traps are given in Table V. With the exception of the Lago Azul Cave, the number of species captured on both traps was different at all the localities. When these measurements were calculated for all localities the values indicated that the sand flies were attracted almost equally by the two traps. If the number of species and the quantity of specimens captured are considered as they are in Margalef's Index, the values for the black trap are always smaller than those for the white one, though in Fisher et al.'s Index, there is a partial overlapping in the confidence interval.

\section{DISCUSSION}

Internal and external stimuli affect the whole process of host-seeking, blood feeding and subsequent rest of the biting flies. In this process, as cited by Browne and Bennett (1981), in a summary of what had been suggested by other authors (Laarman 1955, 1958, Smith 1966, Golini 1970), Bradbury (1972) identified four phases: (i) appetitive behaviour, consisting of five stages: 1 st - habitat selection, 2nd - upwind orientation, 3rd - near orientation, 4th - landing behaviour and 5th - crawling and burrowing; (ii) consummatory reaction probing and feeding; (iii) cessation of feeding and (iv) physiological state of rest. The external stimuli consist of visual, physical and chemical cues. The visual cues stimulating the orientation of flies to a host include reflection of light, movement, contrasting actions, size and shape. Among physical 
TABLE IV

Hourly Williams' mean by sex and female/male ratio of Lutzomyia almerioi captured with black and white modified Shannon traps, in the four localities, from June 1998 to March 1999

\begin{tabular}{lrrrrrrr}
\hline \multicolumn{1}{c}{ Sex } & \multicolumn{2}{c}{$\mathrm{f}$} & \multicolumn{2}{c}{$\mathrm{m}$} & \multicolumn{2}{c}{ f/mRatio } \\
\hline Localities & Traps & Black & White & Black & White & Black & White \\
\hline Guaicurus & 1.46 & 0.10 & 0.10 & 0 & $14.6: 1.0$ & - \\
São Miguel & 3.45 & 0.03 & 0.37 & 0.03 & $9.3: 1.0$ & $1.0: 10$ \\
Lago Azul & 4.86 & 0.60 & 0 & 0.11 & - & $5.5: 10$ \\
Pitangueiras & 15.11 & 1.16 & 1.03 & 0.18 & $14.7: 1.0$ & $6.4: 10$ \\
\hline Overall & 6.32 & 0.56 & 0.43 & 0.11 & $14.8: 1.0$ & $5.2: 1.0$ \\
\hline
\end{tabular}

TABLE V

Sorensen's Quotient (SQ), Margalef's Diversity Index (d) and Margalef's standardized Index ( $\mathrm{d} / \mathrm{d}_{\max }$ ) for black

(B) and white (W) traps at the four localities and Index of diversity of Fisher et al. $(\alpha)$, with the confidence interval $(\mathrm{CI}$ of $\alpha)$ at $95 \%$, for the total captures on the black and white traps

\begin{tabular}{|c|c|c|c|c|c|c|c|c|c|c|}
\hline \multirow{2}{*}{$\frac{\text { Localities }}{\text { Index }}$} & \multicolumn{2}{|c|}{ Guaicurus } & \multicolumn{2}{|c|}{ São Miguel } & \multicolumn{2}{|c|}{ Lago Azul } & \multicolumn{2}{|c|}{ Pitangueiras } & \multicolumn{2}{|c|}{ Overall } \\
\hline & B & W & B & W & B & W & B & $\mathrm{W}$ & B & W \\
\hline SQ & \multicolumn{2}{|c|}{0.67} & \multicolumn{2}{|c|}{0.50} & \multicolumn{2}{|c|}{1.0} & \multicolumn{2}{|c|}{0.73} & \multicolumn{2}{|c|}{0.96} \\
\hline d & 1.08 & 2.16 & 1.42 & 2.23 & 1.50 & 2.26 & 0.78 & 0.99 & 1.79 & 2.46 \\
\hline $\mathrm{d} / \mathrm{d}_{\max }$ & 0.100 & 0.202 & 0.090 & 0.141 & 0.067 & 0.10 & 0.009 & 0.011 & 0.015 & 0.021 \\
\hline$\alpha$ & - & - & - & - & - & - & - & - & 2.20 & 3.75 \\
\hline CI of $\alpha$ & - & - & - & - & - & - & - & - & $1.7-2.7$ & $2.4-5.1$ \\
\hline
\end{tabular}

cues are included radiant and convective heat, moisture, sound and surface structure and among the chemical ones, carbon dioxide and components of odour (Laarman 1955, 1958).

When a trap, such as the Shannon-type, is installed in a particular environment, an artificial situation is created, and the animal or human bait comes to play the role of host and the trap its habitat. Under these conditions the attraction that the insects feel is influenced by the combination of these two factors, as is suggested by the observations of Perez et al. (1988), and also by the light sources. Therefore, it is possible that the sand flies after selecting their preferred habitat, here represented by the black or white trap, and landing on it, may in fact be waiting for an opportunity to feed on the host, man, specifically in this case. This seems to explain the greater attraction evidenced in the study of the anthropophilic species $L$. almerioi, N. whitmani and P. punctigeniculata (Galati et al. 1996, 1999).

As the environments in which the experiment was carried out were covered by a forest type "cerradão" vegetation, which threw its shadow on the rocky soil and were very close to caves, it is reasonable to suppose that mammals and coldblooded vertebrates should have their nests or dens in places with little or no light, where the sand flies probably suck their blood meals, during the diurnal as well as the nocturnal period. It is possible to understand the evidently greater attraction exerted by the black trap rather than the white one for the single most frequent species in all the localities, L. almerioi (Table I) since it is closely associated with caves and presents both diurnal and nocturnal activity (Galati et al. 1999). On the other hand, this species seems to have a marked opportunist capacity, since it bites man avidly when he is in or near the caves.

This absolute predominance of $L$. almerioi $(89 \%)$ over the other species (Table I) and its greater preference for black traps, since the black/ white ratio was 11.1:1.0 (Table II) influenced decisively the overall black/white ratio (7.0:1.0). Furthermore, this influence may be observed in Table III, which shows the overall Williams' mean as being very close to the average for Pitangueiras, where these species represented $98.4 \%$ of the specimens captured on the black trap and this locality contributed with $72.2 \%$ of the total number of sand flies captured in the four localities (Table I). 
The two other anthropophilic species, $N$. whitmani and P. punctigeniculata (Galati et al. 1996), although their frequencies were much more reduced than that of L. almerioi, were the only species for which the attractiveness of the black trap was statistically more significant.

This greater attractiveness of black over white for the anthropophilic species observed in this experiment agrees with the observations made on various species of Culicidae (Brett 1938, Gjullin 1947, Brown 1951, 1954, Gilbert \& Gouck 1957, Browne \& Bennett 1981). However, for the phlebotomines, of 111 specimens of $N$. intermedia s. lat., no differentiation was observed on the relative attraction exercised by yellow, white, green and red lights, in urban captures with New Jersey traps (Gomes \& Galati 1994).

As the purpose of this study was to use the Shannon trap for the capture of females for dissection to observe natural infection with flagellates, the black trap clearly obtained the best response for this end, since the female/male ratio of the predominant species $L$. almerioi was for the black trap 14.8:1.0, and for the white 5.2:1.0.

The fauna captured in the two traps presented great similarity (Table V) as shown by Sorensen's Quotient (0.96), close to 1.0 that represents maximum similarity. However, excepting Lago Azul, in the three other localities, this quotient varied between 0.50 and 0.73 and the greatest number of species was always captured on the black trap (Table I). Although, Margalef's Diversity Index is the greatest for the white trap in all localities, the difference is small and according to that of Fisher et al., calculated for the overall captures, there is an overlapping in the confidence intervals for the two traps (Table V).

In qualitative terms, it is much easier to see the sand fly when it has landed on the walls of the black trap than on those of the white, because of the contrast between the brightness of the insect's body and the black cloth.

In brief, in the circumstances under which this study was undertaken, it was possible to demonstrate the superiority of the black modified Shannon trap over the white regarding the number of sand flies collected, mainly of the anthropophilic species, the black trap accounted for seven times more than the white, the females being much more strongly attracted to the black trap than the males and with no significant difference between the traps' diversity at the 0.05 level.

\section{REFERENCES}

Bradbury WC 1972. Experiments and Observations on the Near Host Orientation and Landing Behaviour of Simuliidae (Diptera), unpubl. MSc. Thesis, Me- morial University of Newfoundland, 139 pp. (apud Browne \& Bennett 1981).

Brett GA 1938. On the relative attractiveness to Aedes aegypti of certain coloured cloths. Trans $R$ Soc Trop Med Hyg 32: 113-24.

Brown AWA 1951. Studies of the responses of the female Aedes mosquito. Part IV. Field experiments on Canadian species. Bull Entomol Res 42: 575-82.

Brown AWA 1954. Studies of the responses of the female Aedes mosquito. Part VI. The attractiveness of coloured cloths to Canadian species. Bull Entomol Res 45: 67-78.

Browne SM, Bennett GF 1981. Response of mosquitoes (Diptera: Culicidae) to visual stimuli. J Med Entomol 18: 505-21.

Galati EAB 1995. Phylogenetic systematics of Phlebotominae (Diptera, Psychodidae) with emphasis on American groups. Bol Dir Malariol San Amb 35(Supl. 1): 133-142.

Galati EAB, Nunes VLB 1999. Descrição de Lutzomyia (Lutzomyia) almerioi, sp. n. (Diptera, Psychodidae, Phlebotominae) do Mato Grosso do Sul, Brasil. Revta Brasil Ent 43: 277-285.

Galati EAB, Nunes VLB, Dorval MEC, Boggiani PC, Shaw JJ, Cristaldo G, Rocha HR, Andrade RMG, Oshira ET, Casanova C, Naufel G 1999. Ecological aspects of the phlebotomine fauna from Serra da Bodoquena, Mato Grosso do Sul State, Brazil. III International Symposium on Phlebotomine Sandflies, Montpellier, Programme \& Abstracts, p. 38.

Galati EAB, Nunes VLB, Dorval MEC, Oshiro ET, Cristaldo G, Espíndola MA, Rocha HR, Garcia WB 1996. Estudo dos flebotomíneos (Diptera, Psychodidae), em área de leishmaniose tegumentar, no Estado de Mato Grosso do Sul, Brasil. Rev Saúde Pública 30: $115-128$.

Gjullin CM 1947. Effects on clothing color on the rate of attack of Aedes mosquitos. J Econ Entomol 40: 326-327.

Gilbert IH, Gouck HK 1957. Influence of surface color on mosquito landing rates. J Econ Entomol 50: 678680.

Golini V 1970. Observations on Some Factors Involved in the Host-seeking Behavior of Simuliids (Diptera) in Ontario and Norway, unpubl. MSc. Thesis, McMaster University, 230 pp. (apud Browne \& Bennett 1981).

Gomes AC, Galati EAB 1994. Lâmpadas coloridas em armadilha New Jersey para coleta de flebotomíneos (Diptera: Phlebotominae) em área urbana. Rev Ciênc Farm S Paulo 15 (Supl.): 58.

Haddow AJ 1960. Studies on the biting habits and medical importance of East African mosquitos in the genus Aedes. I - Sugenera Aedimorphus, Banksinella and Dunnius. Bull Entomol Res 50: 759-779.

Hayek L-AC, Buzas MA 1997. Surveying Natural Populations, Columbia University Press, New York, 448 pp.

Laarman JJ 1955. The host-seeking behaviour of the malaria mosquito Anopheles maculipennis atroparvus. Acta Leinden 25: 1-144 (apud Browne \& Bennett 1981). 
Laarman JJ 1958. The host-seeking behaviour of anopheline mosquitoes. Trop Geogr Med 10: 293305 (apud Browne \& Bennett 1981).

Maroli M, Feliciangeli MD, Arias J 1997. Metodos de Captura, Conservacion y Montaje de los Flebotomos (Diptera: Psychodidae), OPS/OMS/HCP/HCT/95/ 97, Washington D.C., 72 pp.

Natal D, Marucci D 1984. Aparelho de sucção tipo aspirador para captura de mosquitos. Rev Saúde Pública 18: 418-420.

Perez JE, Villaseca A, Llanos-Cuenta A, Campos M, Guerra H 1988. Técnicas para colectar "titiras" (Lutzomyia spp., Diptera: Psychodidae), en ambientes altoandinos peruanos. Rev Peru Ent 30: 77-80.

Siegel S 1975. Estatística Não Paramétrica para Ciências do Comportamento, McGraw Hill, São Paulo, 350 pp.
Service MW 1993. Mosquito Ecology: Field Sampling Methods, Chapman \& Hall, London, 988 pp.

Sippel WL, Brown AWA 1953. Studies of the responses of the females Aëdes mosquito. Part V. The role of visual factors. Bull Entomol Res 43: 567-574.

Shannon R 1939. Methods for collecting and feeding mosquitos in jungle yellow fever studies. Amer $J$ Trop Med Hyg 19: 131-148.

Smith SM 1966. Observations on Some Mechanisms of Host-finding and Host Selection in the Simuliidae and Tabanidae (Diptera), unpubl. MSc. Thesis, McMaster University, 144 pp. (apud Browne \& Bennett 1981).

Vexanet JA, Barreto AC, Cuba CC, Marsden PD 1986. Características epidemiológicas da leishmaniose tegumentar americana em uma região endêmica do estado da Bahia. III. Fauna flebotomínica. Mem Inst Oswaldo Cruz 81: 293-301. 